\title{
Time to start intervening in the human germline? A utilitarian perspective
}

Kevin Smith

This is the peer reviewed version of the following article:

Smith, K. (2019) 'Time to start intervening in the human germline? A utilitarian perspective'. Bioethics 34(1): pp.90-104.

which has been published in final form at DOI: 10.1111/ bioe.12691

This article may be used for non-commercial purposes in accordance with Wiley Terms and Conditions for SelfArchiving 


\section{bioethics}

TIME TO START INTERVENING IN THE HUMAN GERMLINE? A UTILITARIAN PERSPECTIVE

\begin{tabular}{|r|l|}
\hline Journal: & Bioethics \\
\hline Manuscript ID & BIOT-2858-07-18-SI.R2 \\
\hline Manuscript Type: & Original Article \\
\hline Keywords: & $\begin{array}{l}\text { utilitarianism, genetic engineering, germline modification, genetic } \\
\text { modification, CRISPR }\end{array}$ \\
\hline \multicolumn{2}{|l}{} \\
\hline
\end{tabular}

\section{SCHOLARONE \\ Manuscripts}




\footnotetext{
${ }^{1}$ Melo EO, Canavessi AMO, Franco MM, Rumpf R. (2007). Animal transgenesis: State of the art and applications. J Appl Genet. (48)1:47-61.

${ }^{2}$ Smith K. Theoretical mechanisms in targeted and random integration of transgene DNA. (2001). Reproduction Nutrition Development. 41(6):465-485.

${ }^{3}$ Chen Y, Niu Y, Ji W. (2016). Genome editing in nonhuman primates: Approach to generating human disease models. J Intern Med. 280(3):246-251; Lotti SN, Polkoff KM, Rubessa M, Wheeler MB. (2017). Modification of the genome of domestic animals. Anim Biotechnol. 28(3):198-210; Shrock E, Guell M. (2017). CRISPR in animals and animal models. Crispr in Animals and Animal Models. 152:95-114.

${ }^{4}$ Zinc-finger nucleases.

${ }^{5}$ Transcription activator-like effector nucleases.

${ }^{6}$ Clustered Regularly Interspaced Short Palindromic Repeats.

7 Sommer D, Peters AE, Baumgart A, Beyer M. (2015). TALEN-mediated genome engineering to generate targeted mice. Chromosome Res. 23(1):43-55; Gupta RM, Musunuru K. Expanding the genetic editing tool kit: ZFNs, TALENs, and CRISPR-Cas9. J Clin Invest. (2014). 124(10):4154-4161; Ohtsuka M, Sato M, Miura H, et al. IGONAD: A robust method for in situ germline genome engineering using CRISPR nucleases. Genome Biol. (2018). 19:25.
} 
showing the greatest potential, largely due to the relative ease with which their sequence-recognition component can be programmed to target specific sites within the genome. ${ }^{8}$

Very recently (November 2018), scientist He Jiankui, at the Southern University of Science and Technology of China, announced the creation of the first GM babies. ${ }^{9}$ This work was apparently conducted in secret and, at the time of writing, has not been published in a peer-reviewed journal. Via a video posted on YouTube, He claims to have impregnated a woman with CRISPR gene-edited embryos, resulting in the birth of healthy twin girls. The modification entails knock-out of a genetic pathway exploited by HIV to infect cells. ${ }^{10}$ At a conference, He subsequently claimed that there is another pregnancy. ${ }^{11}$ The Chinese government has recently confirmed the births. ${ }^{12}$

GM technology in general has generated a wide array of ethical concerns, and human germline genetic modification (HGGM) has engendered the greatest disquiet. ${ }^{13}$ It was no surprise that news of He's experiment immediately led to a vociferous outcry of moral condemnation from media, society and many academics. More deliberatively, bioethicists have applied a broad range of normative approaches to various aspects and forms of GM. Utilitarianism is one of the most powerful of these approaches; this paper will evaluate the ethics of HGGM from a Utilitarian perspective.

\section{UTILITARIANISM}

Utilitarianism is predicated upon the principle that ethical judgements should be based on the consequences arising, or likely to arise, from a course of action. Desirable consequences are those in which positive mental states (happiness, or 'Utility') outweigh negative mental states (suffering, or 'Disutility'), in aggregate across all affected individuals. ${ }^{14}$

While it is not a flawless moral theory, Utilitarianism possesses key features which render it valuable, including a high degree of internal consistency and a rational, analytical approach. Importantly, because happiness and suffering (in all their forms) are, respectively, highly valued and strongly deprecated by virtually all agents, conclusions generated by Utilitarian analysis arguably have the potential for broader acceptance than those derived using theories based on nonconsequentialist principles or religious precepts. Utilitarianism is particularly powerful as a tool for deciding whether the risk-benefit ratio of a proposed course of action is favourable - a central issue in much clinical and research ethics work.

\footnotetext{
${ }^{8}$ Hatada I, Horii T. (2016). Genome editing: A breakthrough in life science and medicine. Endocr J. 63(2):105110; Mussolino C, Mlambo T, Cathomen T. Proven and novel strategies for efficient editing of the human genome. Current Opinion in Pharmacology. (2015). 24:105-112.

${ }^{9}$ Cyranoski D, Ledford H. (2018). International outcry over genome-edited baby claim. Nature. 563(7733):607608; Normile D. (2018). Shock greets claim of CRISPR-edited babies. Science. 362(6418):978-979; Thulin, L. (2018).

${ }^{10}$ The He Lab. (2018). About Lulu and Nana: Twin Girls Born Healthy After Gene Surgery As Single-Cell Embryos. Retrieved from https://www.youtube.com/watch?v=th0vnOmFltc\&app=desktop

${ }^{11}$ Greenfield A. Fearful old world? (2019). A commentary on the second international summit on human genome editing. Mammalian Genome. Lovell-Badge R. (2019). CRISPR babies: A view from the centre of the storm. Development. 146(3); What's New, and What's Not, in the Reported Birth of the CRISPR Babies. Retrieved from https://www.smithsonianmag.com/science-nature/whats-new-whats-not-reported-birthcrispr-babies-180970935/\#wzBVAsMXFKlijFfQ.99.

12 South China Morning Post. (2019). China confirms birth of gene-edited babies, blames scientist he jiankui for breaking rules. Retrieved from https://www.scmp.com/news/china/science/article/2182964/china-confirmsgene-edited-babies-blames-scientist-he-jiankui

${ }^{13}$ van Dijke I, Bosch L, Bredenoord AL, Cornel M, Repping S, Hendriks S. (2018). The ethics of clinical applications of germline genome modification: A systematic review of reasons. Human Reproduction. 33(9):1777-1796.

${ }^{14}$ Scarre, G. (1996). Utilitarianism. London: Routledge.
} 
While some ethicists (including the present author) are committed Utilitarians, most are not. For example, Kantians, Christian ethicists and Virtue ethicists work from precepts that are wholly different from, and largely incommensurate with, Utilitarian principles. Indeed, some ethicists are strongly opposed to Utilitarianism. Inevitably, many non-Utilitarian moral philosophers will disagree with the modus operandi of this article. However, most bioethicists are neither Utilitarians nor pure deontologists: many subscribe to some form of value pluralism, or sidestep foundational questions by relying on Principlism ${ }^{15}$ or Casuistry ${ }^{16}$. While such non-Utilitarian bioethicists do not consider Utility as decisive, most do consider it to be a relevant factor in ethical deliberations. Moreover, Utilitarian concepts are often borrowed by non-Utilitarian ethicists, such as Principlists and some Kantians. ${ }^{17}$ Accordingly, this paper is of potential interest to a broad audience, including non-Utilitarian bioethicists. I suggest that it should be read by non-Utilitarians as offering pro tanto Utility-based arguments concerning the ethics of HGGM, which can be weighed against fundamental questions of ethical theory, consideration of which lies beyond the scope of this paper.

Several variants of Utilitarianism exist. ${ }^{18}$ Some forms seek to maximise Utility through indirect means; for example, through maximisation of preference satisfaction, or by establishing ethical rules to be followed in lieu of case-by-case Utility calculation. These variants, while being valuable in certain contexts, will not be used in the present paper. Instead, I shall employ a hedonistic Utilitarian approach, focusing directly on the metal states of individuals. ${ }^{19}$ Such Utilitarian deliberation entails cost-benefit analysis based upon an approximate quantification of Utility change, and this will be the approach taken in this paper in considering the ethics of proceeding with HGGM.

\section{HGGM: PROSPECTS AND LIMITATIONS}

Once the technology is fully developed, the prospects for HGGM are substantial. Where the genome of one or both of a pair of prospective parents contains a known genetic sequence that causes a specific disorder, a bespoke GM strategy could permanently correct the disorder-associated sequence in an embryo conceived from these parents. In principle, this would offer a tantalising means for parents to eliminate or greatly reduce the risk of their child developing the disease in later life. ${ }^{20}$ It would also avoid the disorder-associated sequence being transmitted to any future descendants of the GM child.

Many common disorders, such as neuropsychiatric disorders (e.g. schizophrenia, autism), are polygenic in nature, meaning that several disparate genetic loci are involved, each serving as a risk

\footnotetext{
${ }^{15}$ Beauchamp, T. L, \& Childress, J. F. (1994). Principles of biomedical ethics. New York: Oxford University Press. ${ }^{16}$ Jonsen, A. (1995). Casuistry - an alternative or complement to principles. Kennedy Institute of Ethics Journal, 5(3), 237-251.

${ }^{17}$ The ethicist R.M. Hare was perhaps the most prominent example of this, with his work explicitly blending Kantian and Utilitarian principles. (Hare, R.M. (1996). Essays on Bioethics. New York: Oxford University Press). ${ }^{18}$ The Utilitarian community itself is not monolithic, and I do not claim to speak for all Utilitarians. Many of those who consider themselves as Utilitarians will not necessarily accept all (or any) of the arguments and conclusions I present in this paper. Utilitarianism is not dogma, nor is it a scientific system for attaining absolute ethical truth. As with all plausible ethical approaches, there is always room for doubt and alternative conclusions amongst those who subscribe to its basic tenets.

${ }^{19}$ The hedonistic form of Utilitarianism has been employed in this paper for two reasons, one pragmatic and one philosophical: it is a relatively straightforward tool of analysis, compared with alternative Utilitarian approaches; and it deals unambiguously with the central feature of Utilitarianism, namely Utility. ${ }^{20}$ While HGGM has the potential to produce individuals who will avoid a disease that they otherwise would have been at risk of developing, it is arguably not a form of therapy, because it cannot treat any existing person. While GM can treat an embryo, it cannot treat a child on its way to coming into being, as this person (with the disease) would not exist if the GM intervention had not occurred. Accordingly, the term therapy (as in 'germline gene therapy', etc) will be avoided in this paper.
} 
factor. Thus, a future goal of HGGM would be the ability to simultaneously modify multiple genomic sites in an individual embryo.

The human germline per se is by no means 'perfect', with evolution having furnished us with rather minimal protection from diseases that tend to strike after the reproductive years. Humans in general are thus at risk from an array of genetically mediated medical problems including cancers and various degenerative disorders. In the future it will likely become possible to modify the human genome to protect against some of these common disorders. This has previously been achieved to an extent in GM experiments on non-human animals (mainly mice). ${ }^{21}$ If several common disorders could be avoided or delayed by HGGM, the average disease-free lifespan could be substantially extended.22

Through disease-avoidance and disease-reduction, HGGM promises to boost Utility, and is thus a prima facie candidate for Utilitarian support. Increased Utility can be envisaged at two levels, individual and population. At the former level, HGGM would avoid suffering by the GM individual (and their loved ones) had the intervention not occurred. Regarding the population level, it is apposite to imagine two possible worlds: World $A$, with no HGGM, and World $B$, in which HGGM is used. World $A$ will contain more disease and debility, and thus lower overall Utility, compared with World B. Utilitarians thus have good reason to support HGGM in principle, as a means to reducing future suffering. However, as with any new biotechnological innovation, questions of safety exist: if a GM approach inflicted genetic damage that led to increased suffering, this would be a Disutility, counting against it. More fundamentally, all currently plausible forms of HGGM would require IVF procedures, which would be costly and burdensome for prospective parents. And the availability of HGGM may have the unintended consequence of discouraging the adoption of children. The Disutility arising from these negatives must be factored into the Utilitarian calculus.

New GM technologies have moved us closer to the above prospects for HGGM. Applied to animal embryos, CRISPR technology can reliably induce highly specific genomic alterations, and it can be used to perform multiple locus alterations in a single embryo. ${ }^{23}$ Efficiency rates for CRISPR are already high and are continuing to improve, and very low rates of unintended mutations now regularly achieved. ${ }^{24}$ Nevertheless, the technology is not yet at a stage where it could reliably deliver many of the more ambitious goals above. This is compounded by an additional limitation: our scientific understanding of the links between genetic sequences and health remains at an elementary stage. While we have detailed genetic knowledge of many monogenic disorders, such as cystic fibrosis (CF), Duchenne muscular dystrophy (DMD), and Huntington's disease (HD), we know far less about the genetic aetiology of polygenic disorders, such as cardiovascular disease, diabetes, and neuropsychiatric disorders. Therefore, many of the GM applications outlined above remain purely theoretical at present.

Looking further into the future, GM technology will likely become highly efficacious. This promises several Utility-promoting benefits, including correction of the random mutational damage that naturally occurs in everyone's germline cells, and reversal of previous deliberate genetic

\footnotetext{
${ }^{21}$ For example, the addition of extra copies of tumour-suppressor genes to mice embryos has substantially reduced the resultant animals' risk of cancer (for example see: Klatt, P. \& Serrano, M. Engineering cancer resistance in mice. Carcinogenesis 24; 2003; 24: 817-826). Applied to humans, such genome engineering has the theoretical potential to reduce general cancer risk, with the descendants of the genetically modified individual also benefitting from the reduction in risk.

22 Olshansky SJ, Perry D, Miller RA, Butler RN. (2006). In pursuit of the longevity dividend. Scientist. 20(3):2837.

${ }^{23}$ See for example: Lee, H. K, Willi, M, Smith, H. E, et al. (2019). Simultaneous targeting of linked loci in mouse embryos using base editing. Scientific Reports, 9, 1662. Zhang, J, Cui, M, Nie, Y, et al. (2018). CRISPR/Cas9mediated specific integration of fat-1 at the goat MSTN locus. Febs J, 285(15), 2828-2839.

${ }^{24}$ See for example: Li C, Zhou S, Li Y, et al. (2018). Trio-based deep sequencing reveals a low incidence of offtarget mutations in the offspring of genetically edited goats. Frontiers in Genetics. 9:449. Midic, U, et al. Quantitative assessment of timing, efficiency, specificity and genetic mosaicism of CRISPR/Cas9-mediated gene editing of hemoglobin beta gene in rhesus monkey embryos. Hum.Mol.Genet. 26; 2017; 26: 2678-2689.
} 
modification should this ever be required. It might also become possible to genetically modify sperm cells. Although genetic engineering of sperm is inherently limited to modifying only the paternal contribution to the child's genome, a sperm-mediated approach in combination with artificial insemination (Al) would make intervening in the germline much easier (and cheaper) than embryobased approaches. This would permit widespread use of HGGM, as opposed to the technology being available only to affluent nations or individuals. ${ }^{25}$

Beyond modifications to prevent disease, future GM technology could also be used to enhance normal human functioning. Enhancements might include improvements to abilities such as eyesight, physical strength, or endurance. The brain might also be enhanced, such as to boost cognitive ability (this has already been achieved in genetically modified mice ${ }^{26}$ ), or -most controversially- to alter morally-relevant behavioural tendencies. ${ }^{27}$

\section{THE IMPORTANCE OF EARLY USE OF TECHNOLOGIES}

It is valid, and necessary, to discuss the ethical implications arising from highly futuristic HGGM applications, such as the creation of humans with enhanced abilities, because it seems inevitable that the technology will, one day, become good enough to reliably alter the germline such that these scenarios are no longer science fiction. However, this paper will put distant future possibilities aside and focus instead on the technology as it currently exists, in order to address the ethics of applying available GM techniques to humans. This early-use possibility is of prime ethical interest per se; and it is also important in that the initial attempts at modifying the human genome will serve as the crucial first steps towards more advanced applications. ${ }^{28}$

The importance of 'first steps' can be illustrated with the paradigm case of IVF. Hitherto restricted to animals, in the 1970s IVF was attempted with a human couple, leading to the birth of a healthy child. This bold step -which was conducted in secret and largely avoided prior ethical scrutinykickstarted the revolution in IVF that has transformed the treatment of infertility. ${ }^{29} \mathrm{Had}$ risk-averse precaution been enacted at the time, preventing the first-use human IVF attempt, the development of this valuable reproductive technology would likely have been delayed substantially.

However, by citing the IVF case I am not arguing for a simple laissez-faire approach towards HGGM. The first IVF attempt can be criticised on various ethical grounds. And a lack of caution in medicine can lead to serious negative outcomes, as evidenced by medical tragedies such as the

\footnotetext{
${ }^{25}$ K. Smith and C. Spadafora. Sperm-mediated gene transfer: applications and implications. Bioessays 27; 2005; 27: 551-562.

${ }^{26}$ Lehrer J. (2009). Small, furry .. and smart. Nature. 461(7266):862-864.

${ }^{27}$ Harris J. (2010). Enhancing evolution: The ethical case for making better people. New Jersey: Princeton University Press.

28 In one sense, it can be said that the human germline has been subject to intervention since the late 1990s, because a (small) number of babies have been born following 'mitochondrial replacement therapy' (MTR). MTR is carried out at the oocyte/embryo stage, and a number of different MTR techniques have been developed: in all cases the goal is to ensure that native (mutation-containing) mitochondria are replaced with mitochondria from a donor individual. MTR thus allows a woman whose mitochondria contain a mutated gene to produce a child who will not inherit the disease associated with the mutation-carrying mitochondrial genome. However, while MTR is certainly of ethical importance, and may be described sensu stricto as 'GM', MTR comprises a bulk swapping of entire sets of genes (i.e. those contained within the mitochondria), as opposed to the specific modification of genetic sequences via GM technologies such as CRISPR. This places MTR in a separate category from HGGM as commonly understood. Thus, detailed consideration of MTR lies outside the scope of the present paper. For further discussion on the distinction between MTR and HGGM of the sort that is the subject of the present paper, see:Newson AJ, Wrigley A. (2017.) Is mitochondrial donation germ-line gene therapy? Classifications and ethical implications. Bioethics.;31(1):55-67. For a discussion of the ethics of MTR see:Rulli, T. (2016). What Is the Value of Three-Parent IVF? Hastings Center Report 46(4): 38-47. 29
} 
epidemic of birth defects caused by the inadequately tested drug thalidomide. ${ }^{30}$ Moreover, an early attempt to apply a new technology that results in failure or damage to health risks doing the converse of priming a biomedical revolution, producing instead a proscriptive response from society and regulators. If the technology in question is inherently of potential benefit, the chilling effect on its development resulting from a failed early attempt would be an unfortunate and undesirable consequence.

The claimed creation of the first GM humans by He Jiankui, as described above, is apposite here. The possibility exists that He's experiment will prove to have been safe and successful. But from what is known so far, the portents are not good. This is so for several reasons, including:

- The experiment was designed to create children who would be resistant to infection from a particular strain of HIV; all the children were produced using sperm from fathers infected with HIV, but there was no need to use GM for this purpose, as sperm-washing techniques are available that reliably remove HIV particles from sperm.

- Independent scientists examining preliminary data have expressed concerns that there appears to be evidence of mosaicism in placental material and an off-target edit in one embryo sample. These occurrences, if they have affected the GM babies, could mean that the goal of HIV resistance has not been achieved, and they raise safety concerns.

- There are questions around whether institutional ethical approval was obtained for the work.

- It is unclear whether the parents had freely given their informed consent.

The response to He's experiment from media and society has been heavily negative, and it seems likely that scientific freedom in this area will be curtailed rather than liberated by what appears to have been an ill-conceived, ethically fraught and not entirely successful experiment. However, the seemingly botched nature of He's attempt does not imply that HGGM is inherently undesirable. As described above, major benefits to humanity are likely to accrue from the ability to modify the human genome. Realisation of these benefits depends upon the development of effective HGGM technologies, and such development cannot come to fruition in the absence of actual attempts to create GM humans. As opposed to simply banning HGGM -as called for by many commentators following He's experiment- for Utilitarians the correct approach to decide whether it is right to proceed at the present time with HGGM is to weigh up the relevant risks and probable benefits in terms of their likely effects on Utility.

\section{EARLY-USE POSSIBILITIES}

The disorders most amenable to GM technology are monogenic conditions with high penetrance, in which the association between gene and phenotype has been thoroughly established. For such disorders an appropriate GM strategy could be devised based on current technology which could be applied to embryos from parents whose genome(s) harbour the aberrant gene. Because the necessary technology is well established in transgenic animal research, such a strategy should have a high probability of success; and the concomitant avoidance of an otherwise inevitable serious medical condition would yield a high Utility. This combination of high magnitude and probability of benefit gives Utilitarians prima facie reason to view serious high-penetrance monogenic conditions as appropriate candidates for early-use HGGM.

However, well-characterised monogenic disorders can already be avoided using existing technology, namely pre-implantation genetic diagnosis (PGD). ${ }^{31}$ Consider for example sickle cell anaemia (SCA). This severe form of anaemia is associated with serious health problems including pain,

\footnotetext{
30 Vargesson, N. (2015).Thalidomide-induced teratogenesis: History and mechanisms. Birth Defects Research. 2: 140-156.

${ }^{31}$ Harper JC. (2018). Preimplantation genetic screening. J Med Screen. 25(1):1-5,
} 
swelling, infection, and cardiovascular damage. ${ }^{32}$ SCA occurs in individuals homozygous for a mutated $\beta$-globin gene. Where a pair of prospective parents are heterozygotes, there is a 1 in 4 probability that any child they produce will be homozygous for the mutant gene, and thus develop SCA. However, PGD can be utilised in such cases: IVF is used to produce embryos, which are grown briefly in vitro until comprising a suitable number of cells, at which point a biopsy is taken for genotype testing. Embryos typed as homozygous (or heterozygous) for the wild-type $\beta$-globin gene can then be selected for uterine transfer and gestation.

GM could in principle be used to the same end. Experiments with cells have established that it is possible to use GM techniques to correct the mutant $\beta$-globin gene. ${ }^{33}$ Adapting this to the human embryo, a possible strategy would involve delivery of CRISPR biomolecules designed to target the $\beta$ globin gene, along with a correction template DNA molecule based on a wild-type $\beta$-globin gene sequence; the template sequence would interact with the genome at the CRISPR-targeted location, in a process known as homology-directed repair (HDR), thus overwriting and correcting the genetic aberration. ${ }^{34}$ Treated embryos would then be grown in vitro and subject to genetic sequencing, to allow selection of embryos in which the desired modification had been achieved.

Various CRISPR-based strategies are possible for other monogenic disorders, with proof-of concept demonstrated in cell and animal GM studies. For example, DMD, an X-linked disorder dominant caused by a non-functional dystrophin gene, might be avoided by using CRISPR to delete a key RNA splicing sequence, allowing a modified functional gene product to be expressed. ${ }^{35}$ And some dominant disorders might be avoided by using CRISPR to knock-out an aberrantly expressing gene, such as mutant huntingtin in HD. ${ }^{36}$

Because PGD can used to avoid inherited monogenic disorders such as SCA, DMD and HD, it would arguably be ethically problematic to attempt GM as an alternative. Use of the former technology in humans is well established and has no special safety concerns (beyond the risks associated with IVF), while GM approaches are unproven in practice. I will argue later in this paper that the health risks from current GM techniques are likely to be low. However, any additional risk would be difficult to justify, given that present GM technology offers no clear advantages over PGD for these conditions. Nevertheless, Utilitarians have good reason to support attempting GM in place of PGD on the basis that it would bring about an important wider benefit, namely the kickstarting of a revolution in HGGM, leading to the development of technologies able to deal with polygenic conditions and provide broad improvements to human health.

Moreover, in some cases PGD is of no use, namely where all conceptuses will contain the disease-causing sequence. For example, where both prospective parents are homozygous for the mutant $\beta$-globin gene (and thus affected with SCA), no embryo they produce will contain a wild-type $\beta$-globin gene. PGD is also ineffective where one parent is homozygous for a dominant disease-causing allele. For example, an individual whose huntingtin genes are both of the mutant type can only give rise to embryos that contain a disease-causing gene. It is such couples who would be potential candidates for early-use HGGM. A hypothetical couple will be used later in this paper to discuss the

\footnotetext{
${ }^{32}$ Karayalcin, G, Rosner, F, Kim, K.Y, et al. (1975). Sickle-cell anemia - clinical manifestations in 100 patients and review of literature. Am J Med Sci. (269)1: 51-68.

${ }^{33}$ Bauer DE, Brendel C, Fitzhugh CD. (2017). Curative approaches for sickle cell disease: A review of allogeneic and autologous strategies. Blood Cells Molecules and Diseases. 67:155-168.

${ }^{34}$ Devkota, S. (2018). Strategies to enhance the frequency of homology-directed repair (HDR) for increased efficiency of CRISPR/Cas-mediated transgenesis. BMB REPORTS. (51): 437-443; Van den Bosch, M, Lohman, P.H, Pastink, A. (2002). DNA double-strand break repair by homologous recombination. Biological Chemistry. 383:873-892.

${ }^{35}$ Wong TWY, Cohn RD. (2017). Therapeutic applications of CRISPR/cas for duchenne muscular dystrophy. Curr Gene Ther. 17(4):301-308.

${ }^{36}$ Su Yang et al. CRISPR/Cas9-mediated gene editing ameliorates neurotoxicity in mouse model of Huntington's disease. J.Clin.Invest. 127; 2017; 127: 2719-2724.
} 
ethical issues around an early use of HGGM technology. Before this, an important alternative option to HGGM will be discussed: adoption.

\section{IS ADOPTION THE ETHICALLY PREFERABLE SOLUTION?}

Two forms of reproductive technology are available to prospective parents who cannot use PGD: donor insemination and embryo donation. And a third, non-technological way to prevent transmission of a genetic disorder is also available: adoption. Before discussing the ethical aspects of HGGM per se, I shall consider whether adoption might be ethically preferable. This may seem a digression, but it is not: procreative choice is a crucially important factor in the ethics of reproductive technologies, and is thus highly relevant to the ethics of HGGM. ${ }^{37}$

In contrast to PGD or HGGM, donor insemination or embryo donation will produce a child who is genetically related to only one of the parents; and adoption entails that neither parent is related to the child. Many couples have a strong desire to have children that are genetically their own. This wellknown and commonplace -although certainly not universal- strong desire is evidenced by the substantial financial and emotional costs borne by many infertile couples who choose to use reproductive technologies to produce a related child. It is therefore to be expected that many prospective parents at risk of transmitting a genetic disorder, for whom PGD is not possible, will prefer HGGM -if they perceive it to be sufficiently effective and safe- over adoption.

The fact that many prospective parents desire genetic relatedness, and use reproductive technologies to secure a related child over adoption, does not amount to a moral argument in favour of relatedness. ${ }^{38}$ From a Utilitarian perspective, we must ask: which is preferable, [a] adoption, or [b] a technological solution? It is well-known that, worldwide, many orphans are languishing in institutions or surviving on the street; it may reasonably be assumed that they have lives that are on average of substantially reduced happiness compared with other children. Therefore, if option [a] pertains, a substantial Utility gain will occur whenever any of these children become adopted by caring parents with the means to support them. If instead the prospective parents opt for [b], the effect will be to add Utility to the world by creating a child who is likely to experience a happy existence. ${ }^{39}$

It is difficult to assess the relative Utility gains likely from [a] the enhancement of an existing life through adoption versus [b] the creation of an additional happy life, and therefore difficult to determine with certainty which option is preferable. More fundamentally, the notion that the creation of extra happy lives can compete with the quality of existing lives is contentious. Utilitarianism seems to entail that it is ethically desirable to increase Utility through the creation of happy lives, a position I shall refer to as the Utilitarian Total View (UTV). But this view is intuitively unappealing, and leads to what Derek Parfit has famously called the Repugnant Conclusion:

Compared with the existence of many people who would all have some very high quality of life, there is some much larger number of people whose existence would be better, even though these people would all have lives that were barely worth living. ${ }^{40}$

Avoidance of the Repugnant Conclusion (RC) is one of the major motivations for rejecting the UTV. However, rejection of this view seems to imply rejection of Utilitarianism more generally, since the summation of happiness in aggregate is a central Utilitarian principle. Accordingly, some Utilitarians

\footnotetext{
${ }^{37}$ Rulli, T. (2016). The Ethics of Procreation and Adoption. Philosophy Compass 11(6): 305-315.

${ }^{38}$ Rulli, T. (2016). Preferring a Genetically-Related Child. J Moral Philos. 13(6): 669-698.

${ }^{39}$ Not all ethicists agree: anti-natalists hold that to bring a person into existence is inevitably to harm that person. See for example: Benatar, D. (2008). Better Never to Have Been: The Harm of Coming Into Existence. New York: Oxford University Press.

${ }^{40}$ Parfit, D. (1984). Reasons and Persons. New York: Oxford University Press.
} 


\footnotetext{
${ }^{41}$ Huemer M. (2008). In defence of repugnance. Mind. 117(468):899-933;

42 For critical discussions of these arguments, see: ibid; Pummer T. (2013). Intuitions about large number cases. Analysis. 73(1):37-46; Thomas T. (2018). Some possibilities in population axiology. Mind. 127(507):807-832.

43 It may be that anthropogenic climate change requires a smaller population in the future, to avoid a reduction in average Utility through environmental damage. There is no serious scientific doubt that climate change, unless it can be reversed or mitigated, looks set to have major negative consequences for humanity in the future. However, in the context of the present paper, it is likely that children born into the present world will not experience a substantial lowering of average Utility due to the contribution to global warming made by their existence. While some ethicists have argued for restrictions on fertility on account of climate change -see for example: Earl, J, Hickey, C, Rieder, T.N. (2017). Bioethics 31(8): 582-589- others disagree that procreation contributes significantly to global warming - see for example: Lomborg, B. (2018, May 30). Global warming now they're even blaming babies. The Australian. For Utilitarians, the issue of population growth and global warming is complex, and its detailed consideration lies beyond the scope of the present discussion. See for example: Scovronick, N, Budolfson, M.B, Dennig, F, et al. (2017). Impact of population growth and population ethics on climate change mitigation policy. Proc Natl Acad Sci U S A. 114(46): 12338-12343.

${ }^{44}$ Parfit himself, subsequent to conceiving and elucidating his Repugnant Conclusion, has argued in favour of a Limited UTV. For an elucidation of his attempted solution, and a valuable discussion of the flaws of various alternatives to the Total View, see: Parfit D. (2016). Can we avoid the repugnant conclusion? Swedish Journal of Philosophy. 82(2):110-127.
} 
45 It may be possible to 'educate' some of these parents such that they change their mind and willingly opt for adoption instead of a genetically related child, however it would appear implausible to imagine that an educational strategy would persuade the majority of such parents to adopt instead of opt for a technological solution (assuming it to be affordable, safe and effective), given the strong emotional desire for relatedness that is commonly observed among many would-be parents.

46 If the UTV is correct, such reproductive autonomy would also be desirable insofar as it led to the creation of extra (happy) children (through HGGM) who otherwise would not have been born.

${ }^{47}$ Some empirical research has been published on the effect of liberalising reproductive technologies on adoption rates. The results suggest that increased availability of IVF does not appear to drive a reduction in adoption rates. However, this research is of a preliminary nature, and the findings are specific to particular jurisdictional and economic contexts, meaning that generalisation is highly limited. See: Cohen, G. \& Chen, D.L. (2010). Trading-Off Reproductive Technology and Adoption: Does Subsidizing IVF Decrease Adoption Rates and Should It Matter? Minnesota Law Review. 95(2):485-577.

48 This is so especially in Africa; in some regions of sub-Saharan Africa the disease-associated gene is carried by up to ca. $40 \%$ of the population. See: World Health Organisation. Sickle-cell anaemia: report by the Secretariat. World Health Assembly A59/9; 2006.

49 The notion of individual couples, as opposed to a traditional clinical trial involving large numbers of participants, is realistic. Any application of CRISPR would require to be carefully tailored to the genetic constitution of each pair of prospective parents, even where the same genetic disorder is being targeted. Therefore, each initial HGGM attempt is likely to take the form of a bespoke project involving specific couples. However, this is not to say that there will not be a substantial number of couples seeking GM; there may well be large numbers, but each will likely have to receive an individualised treatment. 
This is a complex question, and I shall answer it in several broad stages: I will first consider whether the attempt is likely to be successful; I will then briefly address nonconsequentialist objections to HGGM; before moving to consider issues of harm, risk, consent and precaution.

As described above, CRISPR could be deployed on embryos from Couple $X$, with the aim of correcting of one or both mutant $\beta$-globin genes. Mice are the main testbed for HGGM techniques, and recent studies have consistently shown impressive results for the effectiveness of CRISPR-based germline GM: embryo survival rates of around 95\% following delivery of CRISPR biomolecules and template DNA have been obtained, and HDR-mediated correction rates of over $90 \%$ have been achieved in the surviving embryos. ${ }^{50}$ Such work demonstrates the that CRISPR-based GM can be highly effective.

In 2015, the first CRISPR-mediated GM attempt on human embryos was published: in a study that was widely reported by the news media, researchers in China reported that 71 from 86 (82.6\%) tripronuclear ${ }^{51}$ embryos survived CRISPR treatment, of which 7 (9.9\%) had undergone HDR-mediated modification of the $\beta$-globin gene. ${ }^{52}$ Subsequently, a separate group targeting other genomic sites, also in tripronuclear human embryos, reported similar results (13.0\% HDR). ${ }^{53}$ Most recently, a group targeting the myocardial disease hypertrophic cardiomyopathy (HCM) gene have reported HDRmediated correction in 13 from 18 human embryos, a success rate of $72.2 \%{ }^{54}$ Notably, this latest work employed normal (not tripronuclear) human embryos, which may in part explain the higher success rate. ${ }^{55}$

From the above work, the chances of success of a CRISPR-mediated germline correction in embryos from Couple $X$ should be high. Would this approach likely produce a gene-corrected child in practice? Suppose that, for Couple $X$, superovulation yields 10 eggs (a typical number); from the above findings, we might expect perhaps 8 to survive the necessary IVF and CRISPR procedures. Across the few GM experiments that have been conducted on human embryos, the reported HDR rate varies widely, from around $10 \%$ for the initial studies to over $70 \%$ for the most recent work; thus it is difficult to predict the success rate for Couple X. However, taking a conservative assumption of $25 \%$, this would give 2 embryos with the genetic correction. The necessary embryo biopsy testing step would not be expected to significantly reduce viability, and ongoing pregnancy rates (after 12 weeks) following embryo testing are typically $50-60 \%$ for a transferred embryo. Thus, it is reasonable to anticipate that Couple $X$ will be able to produce a gene-corrected child within a single ovarian cycle. Repeat attempts would also be possible, and would increase the overall chances of success, albeit with Utility costs from the burden of IVF cycles.

If this likelihood of success indeed pertains, what would be the effects on Utility? To answer this, it is necessary to compare the levels of Utility likely from alternative courses of action. Because PGD is not possible for Couple $X$ (as they are homozygotes), the alternatives will be as follows:

\footnotetext{
${ }^{50}$ See for examples: Acosta, S. et al. Use of two gRNAs for CRISPR/Cas9 improves bi-allelic homologous recombination efficiency in mouse embryonic stem cells. Genesis 56; 2018; 56: e23212. Troeder, S.E, et al. An optimized electroporation approach for efficient CRISPR/Cas9 genome editing in murine zygotes. PLoS One 13; 2018; 13: e0196891.

${ }^{51}$ Tripronuclear embryos are abnormal and unable to develop into viable foetuses; their use in place of normal human embryos avoids some regulatory obstacles and popular ethical concerns.

52 Liang P, Xu Y, Zhang X, et al. (2015). CRISPR/Cas9-mediated gene editing in human tripronuclear zygotes.

Protein \& Cell. 6(5):363-372.

53 Lichun Tang et al. CRISPR/Cas9-mediated gene editing in human zygotes using Cas9 protein. Mol.Genet.Genomics 292; 2017; 292: 525-533.

${ }^{54} \mathrm{Ma} \mathrm{H}$, Marti-Gutierrez N, Park S, et al. (2017). Correction of a pathogenic gene mutation in human embryos. Nature. 548(7668):413-419.

${ }^{55}$ Because the previously described apparent creation of actual gene-edited human infants by He Jiankui has not (at the time of writing) been published in a peer-reviewed scientific journal, it is not possible to draw conclusions regarding efficacy from his experiment.
} 

A. Use donor gametes
B. Use a donor embryo
C. Adopt a child
D. Conceive a child naturally
E. Do not have a child.

In the case of alternative A, either donor sperm would be used to fertilise the female's oocyte, or a donor oocyte would be fertilised with the male partner's sperm and transferred into the female's reproductive tract. In terms of invasiveness, a GM approach would entail superovulation, oocyte recovery, and embryo transfer. Because a donor gamete approach entails fewer invasive steps, it should be less burdensome for the mother. In this respect, her Utility level should be higher if a donor gamete approach is used instead of GM. However, this could not fulfil the strong desire that Couple $X$ have for full genetic relatedness: with Al the child would be related only to the mother, or with a donor oocyte, related only to the father. If, given a free choice, the couple prefer the GM approach, this demonstrates that they place a higher value on relatedness than they place on the reduced burdensomeness of a donor gamete approach. If so, their Utility gain would be greater if they created a fully related child via HGGM than if they were denied it and instead reverted to alternative $A .{ }^{56}$

Alternative B (embryo donation) carries approximately the same degree of invasiveness as A, but would be even more problematic in terms Couple X's desire for relatedness, since the child would be related to neither parent. Thus, if the Utility of Couple $X$ would be lower using donor gametes versus HGGM, the use of a donor embryo would result in yet lower Utility, insofar as the happiness of Couple $X$ is linked to the fulfilment of their desire for a genetically related child. In terms of the Utility of the child, the use of any of these techniques -HGGM or the alternatives A or B- should be the same in all cases. ${ }^{57}$ Thus, the personal Utility of Couple $\mathrm{X}$ is the factor of key relevance in the Utilitarian comparison of these techniques. (And for those who accept the UTV, the addition of an extra life would be desirable regardless of which approach was employed.)

The situation is different for alternative $C$ (adoption). If they adopted, Couple $X$ would be increasing the Utility of an existing child. To make a Utilitarian comparison of adoption with HGGM, it is necessary to consider both the Utility of the parents and that of the child. In the previous section, I suggested that, while adoption per se is strongly supported on Utilitarian grounds, the deep desire for genetic relatedness held by many prospective parents implies that society ought to establish an adoption-enhancing rule preventing access to reproductive technologies. However, if Couple $X$ could be consensually persuaded to choose to adopt instead of using HGGM, this would be desirable from a Utilitarian perspective. (This applies with the greatest force to the extent that UTV arguments are deemed invalid.) However, it seems unlikely that logical persuasion or education of such prospective parents about adoption ethics would generally be effective in dislodging strong emotion-based motivations to have related children.

If HGGM is unavailable to Couple $X$, and they place such value on full genetic relatedness that they reject alternatives $A-C$, their only remaining procreative option is $D$ (natural conception). This would produce a child who will develop SCA. While this child may be expected to have an existence that is on balance one of positive Utility, SCA will almost certainly substantially reduce their happiness. By contrast, a child produced using HGGM should (all else being equal) experience an existence of substantially greater happiness. Thus, Utilitarian reasoning leads to the conclusion that it is ethically preferable for Couple $X$ to choose the GM approach rather than natural conception. This option would also tend to increase the Utility of Couple X, since they will avoid inter alia the emotional anguish that

\footnotetext{
${ }^{56}$ It is not necessary to posit that Couple $X$ themselves are Utilitarians to draw this conclusion. Indeed, their motivation to have a child need not be based on a desire for happiness (of themselves or the child); but the effect of allowing them to freely choose their preferred reproductive approach will nevertheless have an effect on Utility, which is what counts in the present (Utilitarian) discussion.

${ }^{57}$ Here I assume that the parents will not treat their child less well than they would a fully related child.
} 
is frequently entailed by parenting a child with a serious disorder. Some would claim that the rigours of coping with an ill child ultimately benefits the psyche, making the parent (and possibly the child) a 'better person'. This Nietzschean claim that adversity makes us stronger -which is also a common feature of several religiously motivated moral perspectives- may have some validity. But from a Utilitarian viewpoint, the justification for choosing to knowingly conceive seriously a ill child instead of healthy child relies on the suffering of those involved (parents and child) being outweighed by the Utility gained through psychologically strengthening. This would pertain where an individual's adversity-improved character leads them to create much good in society. But while this positive balance of Utility may arise in the case of a few individuals - whom we might view as moral saints- it seems unrealistic to imagine that this could apply more generally. I suggest that for most parents and their children the effects of coping with a serious and debilitating lifelong disorder will be a net reduction in their Utility, and one that will rarely be balanced by wider Utility-generating benefits.

Suppose Couple $X$ are denied HGGM: if they value genetic relatedness so highly that they decline alternatives A-C, and if they decide not to conceive a child who will develop SCA, then alternative $E$ (do not have a child) will be the default. This outcome will result in the couple experiencing less happiness than had they been able to produce a child through HGGM. ${ }^{58}$ Therefore, on Utilitarian grounds the no-child option is less desirable than the HGGM option. And for those who accept the UTV, the non-creation of an additional (healthy) life is ethically undesirable as it entails a loss of potential Utility.

Of course, the above assumptions about success rates might be over-optimistic. The GM attempt with Couple $X$ might fail to produce a viable gene-corrected embryo and subsequent child. This would have implications in terms of Utility. An IVF cycle is burdensome for the mother, entailing inter alia ovarian hyperstimulation and oocyte recovery. Pregnancy itself can be arduous - and a failure at this stage can impose a particularly heavy cost, in terms of the emotional impact of miscarriage. However, given that PGD is impossible for Couple $X$, and the only viable disorder-avoiding alternatives (donor gametes/embryo or adoption) are unpalatable for them, their decision to attempt HGGM could be entirely rational, and compatible with Utilitarian reasoning. Assuming they freely consent, having been furnished with an understandable and accurate account of the procedures, likely success rates and uncertainties, their decision to proceed represents a rational bet. If the outcome is failure, Utility falls; whereas if the attempt is successful, the couple's happiness should increase markedly.

Beyond the benefits to Couple $X$ of a successful attempt, the likely effect of kickstarting a HGGM revolution is of substantial societal importance. Once HGGM is in use, it is reasonable to expect the technology to improve, rendering it more reliable, efficacious, and cost-effective. In such a future world, where advanced GM technology has become widely available, one would expect HGGM to be widely used as a disease risk-reducing add-on to conception, as opposed to being employed only in cases of monogenic disorder transmission (such as Couple X). Since most prospective parents are not at high risk of transmitting a severe, high-penetrance disorder, the availability of HGGM should not have a broad impact on procreative decisions; therefore, adoption rates ought not to be substantively reduced. Because such a world would contain a reduced amount of genetically influenced disease, with no substantial impact on adoption choices amongst these prospective parents, its overall level of Utility should be higher than in an equivalent non-GM world.

Thus, because the successful initial use of GM on the human germline is a necessary step in the development of more widely applicable HGGM, I conclude that there exists good reason for going ahead with the sort of GM attempt suggested for Couple X. Initial HGGM attempts would be on a small scale: this is inevitable, given that only a small subset of couples at risk of transmitting a serious genetic condition would be candidates for early HGGM. This means that even if a reduction in net Utility arose through reduced adoption arising from HGGM in this limited context, it would likely be outweighed

58 This is not to say that being childless per se is necessarily a position of reduced happiness. See: Rachels, S. (2014). The Immorality of Having Children. Ethical Theory Moral. (17)3: 567-82 
by the Utility-generating effects of bringing forward the development of advanced, widely applicable HGGM technology. By contrast, a delay in starting to use HGGM with humans would impose a Utility cost, because the time that passes before HGGM starts to yield benefits is time in which extra suffering through genetically influenced disease will occur.

\section{OBJECTION TO EARLY-USE HGGM ATTEMPTS}

Any proposal to proceed with an early attempt at HGGM (such as that suggested above) would undoubtedly be met with a tranche of objections. These would include several well-rehearsed positions and arguments, including claims of unnaturalness, the alleged interests of embryos, questions of identity, fears of eugenics, and simply the 'yuck factor'. ${ }^{59}$ Most of these objections have little to do with Utility, and as such carry negligible weight for Utilitarians. However, where Disutility is implied by any of these objections, it must be factored into the Utilitarian calculus. One source of Disutility would stem from unhappiness experienced by the GM individual regarding their identity, if they became distressed over their unnatural manufacture. ${ }^{60}$ However, this outcome seems rather implausible. Similar concerns should apply to IVF as an infertility treatment, yet there exists no good evidence that people created through IVF suffer unhappiness through knowing that they were produced through an unnatural process.

Another Disutility might be a degree of anxiety or frustration experienced by some bystanders in the face of something happening which they consider as morally outrageous. ${ }^{61}$ A reduction in Utility of this sort will of course be experienced mainly by those who have strong cultural or religious objections to HGGMs. For the Utilitarian, the question is whether such Disutility would outweigh a gain in Utility. A substantive increase in Utility will be expected in the parents who choose to attempt HGGM. (Also, bystanders who support HGGM will, to an extent, be made happier by the knowledge of a HGGM attempt.) And in terms of the pump-priming effect of early-use HGGM, in a future world in which the technology is used to markedly reduce the incidence of disease, there would be substantively less suffering than in an alternative non-HGGM world. In sum, the suffering of antiHGGM bystanders would be outweighed increased Utility arising from HGGM.

\section{GENETIC HARM}

Utilitarians must take seriously the risk of genetic harm that may arise from a HGGM attempt involving Couple X. It is of course the GM child who would be at potential risk of any adverse effects from the CRISPR technology. Discounting the general risks from routine IVF (which are minimal), the specific risks here are twofold: mutations and mosaicism. ${ }^{62}$ Mutations occur when CRISPR biomolecules interact with and alter sequences other than those intended to be modified. This usually involves distal parts of the genome ('off-target' mutations), but can also affect sequences close to the target locus ('on-target' mutations). Mosaicism is the generation of an embryo that comprises cells of differing genetic constitution: some cells genetically modified, and others not. If a mosaic embryo was used to create a person, their body would also comprise a mix of cells. Phenotypically, this might result in a child who goes on to manifest some features of the disorder that was to be avoided by the GM.

\footnotetext{
59 Philip Ball. The art of medicine Unnatural reactions. Lancet 383; 2014; 383: 1964-1965.

${ }^{60}$ Salvi, M. (2001). Shaping individuality: Human inheritable germ line gene modification. Theor Med Bioethics. (22)6: 527-542.

${ }^{61}$ Hughes, J. (2019). A Defense of Limited Regulation of Human Genetic Therapies. Camb Q Healthc Ethic. (28)1: 112-120; Nuffield Council on Bioethics. (2018). Genome Editing and Human Reproduction: Social and Ethical Issues. London: Nuffield Council on Bioethics.

62 Xiao-Hui Zhang et al. Off-target Effects in CRISPR/Cas9-mediated Genome Engineering. Mol.Ther.-Nucl.Acids 4; 2015; 4: e264, Shuo-Ting Yen et al. Somatic mosaicism and allele complexity induced by CRISPR/Cas9 RNA injections in mouse zygotes. Dev.Biol. 393; 2014; 393: 3-9.
} 
Additionally, the occurrence of a GM-induced mutation in combination with mosaicism would render pre-implantation testing problematic, as there would be a risk that the mutation could be missed through analysing only cells that happened not to contain it.

Mutational effects and mosaicism were found to occur at relatively high levels in the early days of CRISPR experimentation. ${ }^{63}$ However, the accuracy of the technology has been rapidly improved through extensive work at the in vitro cell and transgenic animal levels, with several recent experiments showing extremely low levels of CRISPR-induced mutations ${ }^{64}$ or mosaicism. ${ }^{65,66}$ Such progress is also reflected in the abovementioned experiments on human embryos. In the first of these studies, the researchers randomly selected six of their CRISPR-modified embryos for thorough sequencing: of these, off-target mutations were evident in two cases. ${ }^{67}$ By contrast, in the most recent work, all the HDR-corrected GM human embryos obtained were subject to thorough sequencing and no CRISPR-associated mutations were found. ${ }^{68}$

However, a recent prominent study, authored by Kosiski et al, has suggested that mutational damage from CRISPR may arise at a higher rate that hitherto has appeared to be the case. ${ }^{69}$ This research involved GM of various types of mouse and human cells, and discovered that significant ontarget CRISPR-induced mutations had occurred, including large deletions and various complex genomic rearrangements. The Kosicki study was published in a reputed journal and the work is of high quality: accordingly, it has attracted substantial attention and generated some commentary expressing doubts about the potential safety of CRISPR for use with humans. ${ }^{70}$ But the results obtained in the study are of questionable significance in the context of HGGM. The findings are surprising, in that very large mutations are described which should have been detected in previous studies that have used whole genome sequencing or other powerful methods to detect mutations. There are several reasons to suspect that these results may not be representative of CRISPR outcomes in general, as follows. Firstly, the work focuses on a form of editing that depends on non-homologous end joining (NHEJ); this type of editing is known to be error-prone, and is of less relevance to HGGM attempts than provenly reliable approaches, such as those using HDR (as described earlier in this paper). Secondly, many of the reported experiments in the study selected for cells that exhibited loss of target gene function, potentially skewing the results towards unusual large-scale mutational outcomes. Thirdly, the study assayed a narrow range of loci, and these may not be typical of target genes in general. Fourthly, most of the reported experiments used a system for delivering the genome editing components that itself is known to frequently cause genomic rearrangements; such a delivery system would not be appropriate for HGGM. Finally, the cells types used were specialised laboratory

\footnotetext{
${ }^{63}$ Liang, P, Zhang, X, Chen, Y, et al. (2017). Developmental history and application of CRISPR in human disease. J Gene Med. (19)7-7: e2963. Doi: 10.1002/jgm.2963

${ }^{64}$ Op. cit. note 24.

${ }^{65}$ Mehravar, M, Shirazi, A, Nazari, M, et al. (2019). Mosaicism in CRISPR/Cas9-mediated genome editing. Devel Biol. 445(2): 156-162.

${ }^{66}$ To some extent mosaicism correlates with off-target mutational activity, in that highly accurate CRISPR approaches will only deliver the intended modification, so even if (as with earlier forms of CRISPR technology) the biomolecules linger in the embryo beyond the singe-cell stage, they will be less likely to induce additional, unwanted genetic changes in subsequent cells.

67 Puping Liang et al. CRISPR/Cas9-mediated gene editing in human tripronuclear zygotes. Protein \& Cell 6; 2015; 6: 363-372.

${ }^{68} \mathrm{Ma} \mathrm{H}$, Marti-Gutierrez N, Park S, et al. op. cit. note 48.

${ }^{69}$ Kosicki M, Tomberg K, Bradley A. (2018). Repair of double-strand breaks induced by CRISPR-Cas9 leads to large deletions and complex rearrangements. Nat Biotechnol. 36(8):765-771.

${ }^{70}$ For example see: Wellcome Sanger Institute. (2018). Genome damage from CRISPR/Cas9 gene editing higher than thought. Retrieved from https://www.sanger.ac.uk/news/view/genome-damage-crisprcas9-gene-editinghigher-thought; and Brackley, P. (2018). Wellcome Sanger Institute scientists warn CRISPR/Cas 9 gene editing could lead to 'harmful effects'. Retrieved from https://www.cambridgeindependent.co.uk/business/wellcomesanger-institute-scientists-warn-crispr-cas-9-gene-editing-could-lead-to-harmful-effects-9051009/
} 
strains, which probably have different cellular DNA repair process than exist in actual human embryos, and there is good reason to expect that some of these cell types will be particularly prone to mutational errors during editing.

While the Kosicki paper should not be ignored, there is good reason to believe that the low or zero occurrences of mutations and clinically relevant mosaicism reported in most of the recent literature would likely apply to a well-conceived, real-life attempt at HGGM. It does appear to be the case that mosaicism occurred in the He Jiankui HGGM experiment. However, as described above, $\mathrm{He}$ appears to have been operating as a rogue scientist, and his work can hardly be said to have been well conceived. The He case points towards the need for HGGM to only be conducted under well-regulated environments by competent individuals. Most importantly, any ethically acceptable HGGM attempt would incorporate appropriate genetic testing prior to the generation of GM child. This would include preliminary testing work carried out using cells from the prospective parents ${ }^{71}$, to equilibrate the CRISPR and template molecules and to assay for mutational effects (as was conducted as part of the above-mentioned 2017 human embryo study). Subsequent to such testing, embryos would be screened using PGD coupled with deep sequencing to reveal any mutational issues, such that mutated embryos can be rejected.

It would in any case be wrong to assume that a mutation in the child's genome would inevitably have an effect on their health. It is well established that only around $2 \%$ of the human genome comprises protein-coding genes and their linked control elements. This implies that any single random mutation would have an approximate likelihood of 1 in 50 of occurring within one of these crucial regions. However, this figure of ca. $2 \%$ does not include various genomic elements that express non-coding RNA molecules hitherto considered functionless, but for which evidence is accumulating of a role in 'fine tuning' gene expression and thus potentially influencing phenotype. ${ }^{72}$ But theoretical considerations suggest that the functional fraction of the human genome cannot exceed $25 \%$, and is almost certainly considerably lower. ${ }^{73}$ Recent studies indicate that the non-coding functional regions account for around $6 \%$ of the genome, meaning that (in combination with the $2 \%$ above) the total 'target' for a potentially damaging mutation is around $8 \%$ of the genome. ${ }^{74}$ This suggests that a single CRISPR-induced mutation would have only around a 1 in 12 likelihood of occurring in a functionally significant part of the genome.

Even where an individual mutation has occurred in the functionally important $8 \%$ of the genome, and has somehow escaped detection such that it is present in the GM child, in many or most cases there will be no adverse phenotypic effects. This is most likely in the case of the proportion of the genome that expresses non-coding RNA sequences with a functional role. In general, these noncoding RNAs appear to exert only a modest effect on gene expression and, importantly in the context of mutagenesis, their functionality in general does not depend on the high levels of sequence precision that pertains to the ca. $2 \%$ of the genome that comprises protein coding and other vital sequences. ${ }^{75}$ In keeping with this model of low criticality, while association studies have linked these regions with disease, in general they appear to act as risk factors (as opposed to disease determinants), each having

\footnotetext{
${ }^{71}$ Skin fibroblast-derived stem cells would be likely candidates. They were used in the 2017 human embryo study.

72 Mattick JS. (2004). RNA regulation: A new genetics? Nature Reviews Genetics. 5(4):316-323.

RNA regulation: a new genetics?

${ }^{73}$ Graur D. (2017). An upper limit on the functional fraction of the human genome. Genome Biology and Evolution. 9(7):1880-1885.

${ }^{74}$ Wang J, Samuels DC, Zhao S, Xiang Y, Zhao Y, Guo Y. (2017). Current research on non-coding ribonucleic acid (RNA). Genes. 8(12).

75 Patil VS, Zhou R, Rana TM. (2014). Gene regulation by non-coding RNAs. Crit Rev Biochem Mol Biol. 49(1):1632.; Sheng L, Ye L, Zhang D, Cawthorn WP, Xu B. (2018). New insights into the long non-coding RNA SRA: Physiological functions and mechanisms of action. Frontiers in Medicine. 5:244.
} 
a limited contribution to the disease phenotype. ${ }^{76}$ Thus, a CRISPR-induced mutation that alters one of these non-coding elements is unlikely to lead to the child manifesting a genetic disorder.

Even mutations in coding sequence can be functionally silent; for example, affecting part of a sequence in a way which does not change the amino acid constitution of the gene product, or changing it in an insignificant way. Of mutations that do have a negative effect on the gene product or its expression, not all will lead to a genetic disorder; for example, a mutation that knocks-out a crucial developmental gene may result in a non-viable embryo (and thus not give rise to a foetus or child), and some mutations that knock-out gene function will be compensated for by haplosufficiency ${ }^{77}$.

From the above scientific considerations, it seems clear that a well-conceived HGGM attempt, such as that suggested for Couple $X$, is very unlikely to lead to a genetic disorder in the GM child. Nevertheless, it cannot be said that HGGM using current technology would be absolutely risk-free. The question is, are the risks sufficiently low such that it is ethically acceptable to proceed with early use GM?

\section{RISKS IN CONTEXT}

We are faced with a chicken-and-egg dilemma: the real risk rates for CRISPR-based HGGM cannot be determined until a number of children have been produced using this technology. Thus, if human GM were deemed permissible only once direct proof of an acceptably low risk is available, then it could never be permitted. While many opponents of human GM would no doubt support this position, Utilitarians have reason to think otherwise, considering the potential benefits to humanity that are likely to ultimately flow from HGGM.

It is true that an accidental CRISPR-induced mutation could lead to a negative outcome for the health of the child. However, natural reproduction itself is by no means free from mutational risks. Genetic sequencing has been used in a number of recent studies to analyse genetic differences between trios of individual parents and their (naturally conceived) offspring, and the results obtained so far indicate that natural de novo mutations affect the germline at a rate of approximately 70 de novo mutations per generation. ${ }^{78}$ This means that each individual is, on average, expected to harbour around 70 genetic mutations that were not present in either of their parents' genomes, which have arisen in the gametes or conceptus from which the individual developed. Most of these de novo mutations do not cause disease, for the reasons given above. Nevertheless, the risk of genetic disease is positively correlated with the number of mutations in the genome. In epidemiological terms, ca. $1 \%$ of neonates suffer from a clinically important monogenic defect, and a further ca. $2 \%$ suffer from a congenital malformation, with a substantial proportion of these problems likely being the result of $d e$ novo mutations. And several studies have confirmed that the total number of mutations increases

\footnotetext{
${ }^{76}$ Jain S, Thakkar N, Chhatai J, Bhadra MP, Bhadra U. (2018). Long non-coding RNA: Functional agent for disease traits. Rna Biology. (2017). 14(5):522-535; Gomez-Verjan JC, Vazquez-Martinez ER, Rivero-Segura NA, Medina-Campos RH. The RNA world of human ageing. Hum Genet. 137(11-12):865-879.

${ }^{77}$ Haplosufficiency occurs where a single copy of a gene is sufficient for normal functioning; since most genes are present in the genome as two copies (one from each parent), in many cases the functional knockout of one copy does not lead to a negative effect on health. Not all genes, however, display haplosufficiency; for example, two functional copies of certain genes are often required for normal development. And in an individual's genome, there will be genes where only one copy is functional; if the remaining functional copy is knocked out, all function of that gene will be lost.

${ }^{78}$ This value is necessarily approximate, because the field is relatively new and to date the numbers of family trios that have been thoroughly sequenced is quite low. For reports of trio-sequencing studies, see: Hakon Jonsson et al. Parental influence on human germline de novo mutations in 1,548 trios from Iceland. Nature 549; 2017; 549: 519-+, Ziyue Gao et al. Interpreting the Dependence of Mutation Rates on Age and Time. Plos Biology 14; 2016; 14: e1002355, Laurent C. Francioli et al. Genome-wide patterns and properties of de novo mutations in humans. Nat.Genet. 47; 2015; 47: 822.
} 
with parental age, with children from older parents (particularly fathers) on average harbouring a greater number of mutations. ${ }^{79}$

This background of de novo mutations provides some perspective from which to view the risk of mutations from CRISPR-mediated HGGM affecting the genome of a child from Couple X. Of the many new germline mutations that unavoidably arise in the genome of all humans, the majority do not lead to genetic disorders, and thus each such mutation might reasonably be viewed as, on average, contributing an insignificant risk. On this view, the small additional risk from CRISPR ought also to be viewed as insignificant. However, it does not follow from 'we tolerate risk $X$ ' to 'we should tolerate risk $X+n$, where $n$ is smaller than $X$ '. To think otherwise may amount to a context illusion - namely a failure to acknowledge a small potential source of Disutility when it is set in the context of a much larger background of the same.$^{80} \mathrm{It}$ follows that, if the increased risk is to be accepted, it must be worth the anticipated benefits. As discussed above, early HGGM attempts such as that suggested for hypothetical Couple $X$ would be likely to deliver substantive Utility-promoting benefits, including fulfilment of their strong desire to have a genetically related child, and the avoidance of instead creating a non-GM child who will develop SCA. Although it is possible that this gain of Utility might be outweighed by Disutility through discouragement of adoption, the broader effect of promoting the development of more advanced GM technologies with wide future applicability amounts to a substantial Utility boost. The wider future use of HGGM to reduce the incidence of common genetically influenced diseases would almost certainly outweigh the small additional mutational risk associated with current CRISPR technology. Additionally, it is likely that when the HGGM revolution is underway, future technical refinements and advances will be forthcoming that will further reduce the rate of GM-induced accidental mutations.

\section{CONSENT AND HARM}

Another potential objection to the proposed HGGM attempt is that the future child cannot consent to the procedure. In other words, the use of GM would violate the autonomy of the child, because the child must bear the risk of a mutational accident without having a say in the matter. Utilitarians have good reason to respect the principle of autonomy, ${ }^{81}$ and therefore must take the lack-ofconsent charge seriously. However, a principled objection to GM on grounds of autonomy would also entail the rejection of all pre-conception interventions, including IVF and PGD. This conclusion is not viable for Utilitarians, since established technologies such as these clearly lead to beneficial outcomes, and there is no evidence that lack of consent for prenatal interventions has a negative effect on the happiness of the child. More fundamentally, it is not conceptually possible for a lack of consent to cause Disutility, since prenatal consent is impossible. Children cannot consent to being conceived, nor to their genetic constitution, nor to the societal circumstances into which they will be born. Therefore, a strict principle of consent would entail that procreation in general be considered unethical. ${ }^{82}$ This anti-natalist position is manifestly untenable on Utilitarian grounds, because the

\footnotetext{
${ }^{79}$ Simon L. Girard et al. Paternal Age Explains a Major Portion of De Novo Germline Mutation Rate Variability in Healthy Individuals. PLoS One 11; 2016; 11: e0164212, Kevin R. Smith. Paternal age bioethics. J.Med.Ethics 41; 2015; 41: 775-779.

${ }^{80}$ Glover J, Scott-Taggart MJ. (1975). It makes no difference whether or not I do it. Proc Aristotelian Soc. 49:171-209.

${ }^{81}$ Although autonomy frequently functions in ethical discourse as a deontological principle, it is also derivable from Utilitarian considerations. In the long run it would be detrimental to the general wellbeing if the autonomy of individuals were to be routinely disregarded; thus, autonomy serves as a Utility-maximiser and is therefore respected by Utilitarians, albeit not as an absolutely inviolable principle.

82 Robert Ranisch. Germline Genome Editing and the Functions of Consent. American Journal of Bioethics 17; 2017; 17: 27-29.
} 
application of such a restrictive principle would manifestly reduce Utility..$^{83}$ By contrast, a policy based on proxy consent (given by the parents), will increase Utility and thus should be considered ethically appropriate for HGGM, just as it is for established reproductive technologies.

From a Utilitarian perspective, the key issue here is not consent; rather, it is whether the risk of harm outweighs the likely benefits to the future child. If Couple $X$ decide that they must have a child (i.e. non-parenthood is unacceptable to them) and that the child must be fully genetically related to both parents (i.e. they will not accept adoption, donor gametes or a donor embryo), the only family-founding options are:

\section{A. Undergo CRISPR-mediated GM}

-or-

B. Conceive a child naturally.

Option A will (if a viable modified embryo is obtained, and testing shows that the genetic correction has occurred) produce a child who does not develop SCA, but who is at some (albeit low) risk of sustaining a CRISPR-induced unintended mutation, which might impact on the child's health. By contrast, option B will produce a child who is virtually certainly to develop SCA. Confronted with only these two options, Utilitarian reasoning leads to the conclusion that, because outcome $A$ is preferable to outcome $B$, it is ethically preferable for Couple $X$ to choose to undergo CRISPRmediated GM.

If Couple $X$ choose to knowingly conceive a child who will develop a serious disorder when they could have produced a child who will not develop the disorder, have they harmed the child? Most Utilitarians accept the notion of 'impersonal harm', in the sense that a procreative choice that knowingly would create a child who will experiences a life of reduced happiness is an act that causes harm, despite no existing person being harmed when the procreative decision was made. ${ }^{84}$ If a procreative decision is likely to produce a child whose life would not be worth living (i.e. containing more suffering than happiness), then Utilitarians have good reason to view such a child as having been harmed, and indeed wronged, by the decision to proceed. On this view, non-existence (i.e. the no-child option) would be preferable to such a life. Suppose, instead, that a procreative decision will produce a child whose life would be of reduced happiness but would contain more happiness than suffering. Has harm occurred? If an alternative procreative choice was available that would instead have produced a child who would be expected not to have a life of reduced happiness, it follows that (impersonal) harm has indeed resulted. Accordingly, from a Utilitarian perspective it would be wrong to choose to create a child of reduced happiness where an alternative was available. ${ }^{85}$

\footnotetext{
${ }^{83}$ Many will feel instinctively that this anti-natalist position is wrong and reject it on this intuitive basis; it can also be argued that the position amounts to a reductio ad absurdum and accordingly ought to be rejected. Utilitarian logic reaches the same conclusion -that the anti-natalist position ought to be rejected- but for different reasons, as follows. Disutility would flow both from a direct reduction in the happiness of prospective parents (because they are prevented from fulfilling their desire to procreate), and more broadly through entailing an authoritarian restriction of autonomy, which would be inimical to the sort of free society that is considered by most Utilitarians to be conducive to greater Utility compared with repressive societies. Additionally, the inevitable reduction in the population that would follow from application of the anti-natalist position would be rejected by those who ascribe to a UTV, given the concomitant loss of Utility through a lack of creation of future people.

${ }^{84}$ Nicola J. Williams and John Harris. What is the harm in harmful conception? On threshold harms in nonidentity cases. Theor.Med.Bioeth. 35; 2014; 35: 337-351.

85 The reduction in happiness would have to be substantial. This is so in light of the imprecision inherent in evaluating the qualities of different lives (see: Parfit, D, op. cit. note 37). Additionally, a very small reduction in the Utility of the child might be outweighed by gains in Utility elsewhere, such as the mother avoiding Disutility arising from the burdens associated with assisted conception.
} 
In the case of Couple $X$, a decision to conceive naturally would, by creating a child with SCA, result either in a life not worth living or -more likely in the particular case of SCA- a life of substantially reduced happiness. By contrast, HGGM would avoid SCA while imposing a small risk of producing a child with a CRISP-induced genetic disorder. In this specific scenario, i.e. where other reproductive options have been ruled out, HGGM would be the ethically preferable choice.

As discussed above, on the assumption that the UTV is invalid, it might be preferable if those in the same (or equivalent) genetic position as Couple $X$ were to choose adoption instead of HGGM, since this would most likely generate the greatest amount of Utility. However, to the extent that some of these couples would decline adoption due to possessing a strong desire for relatedness, enabling access to HGGM would -despite the (likely very small) risks entailed by current GM technology- result in increased Utility through a reduction in the level of harm that would otherwise accrue when some of these couples chose to conceive naturally. While making the technology available would likely deter some couples from choosing adoption, it would also have the effect of kickstarting the HGGM revolution. This would move us closer to a World in which overall Utility would be substantially elevated due to reduced levels of genetically influenced disease.

\section{PRECAUTIONARY PRINCIPLE}

As discussed above, while the likelihood of harm appears to be low for a first-attempt at HGGM using current technology, the possibility of catastrophic mutational accidents cannot be ruled out, although it is impossible to accurately quantify the actual level of risk until several HGGM attempts have been conducted. For Utilitarians, the presence of some risk should not in itself be an obstacle to the pursuit of HGGM. Nevertheless, opponents of GM often present risk -especially unknown risk- as grounds for absolute proscription. In this context, the 'precautionary principle' (PP) is frequently deployed, explicitly or implicitly, against proposals to develop or deploy new genetic technologies, including HGGM. ${ }^{86}$

The PP is intuitively attractive to many, as it appeals to the deep human heuristic favouring caution. However, the PP implies unacceptably negative, or even absurd, consequences. The strongest version of the PP holds any degree of risk to be unacceptable, irrespective of the potential benefits. Unfortunately, it is impossible to do anything innovative in bioscience or medicine without some risk, or that could eventually lead to undesirable outcomes. ${ }^{87}$ Various attenuated forms of the PP have been proposed, which seek to avoid the absurd implications of the strong PP. ${ }^{88}$ However, such variants inject nonconsequentialist elements - such as the allocation of capriciously high weightings to certain types of risk, for example 'severe' or 'unknown' risks- into the assessment of risk versus benefit. Utilitarians are bound to reject such intrusions, as they can only lead to a skewing of the Utilitarian calculus and a concomitant bias towards prohibition.

Another PP-based objection against proceeding with a germline GM attempt focuses not on risks to the immediate children who may be created with the initial attempts at germline GM, but with

${ }^{86}$ Smith, KR, et al. Human germline GM: scientific and bioethical perspectives. Arch.Med.Res. 43; 2012; 43: 491-513.

${ }^{87}$ For example, a number of patients have died or become seriously ill due to unexpected effects of virusbased agents used in somatic gene therapy clinical trials. If the strong PP had been applied in the domain of somatic gene therapy, the accidental deaths and morbidity would have been avoided, but this would have been to the detriment of the growing number of patients that have benefitted from somatic gene therapy technology to date, and would have excluded any benefits to the future patients that will be treated in increasing numbers as the technology advances. So the PP in its strongest form, if applied, would permit nothing to be done at all!

${ }^{88}$ A. Arcuri. (2007). Reconstructing precaution, deconstructing misconceptions. Ethics Int Aff 21: 359-379; Sandin, P. (1999.) Dimensions of the Precautionary Principle. Human and Ecological Risk Assessment, 5(5): 889907. Harris J, Holm S. (2002). Extending human lifespan and the precautionary paradox. J Med Philos.

27(3):355-368; C. Sunstein. Beyond the precautionary principle. U Penn Law Rev (2003). 151: 1003-1058. 
the spectre of distant harms or other negative outcomes. On this view, a 'slippery-slope' is perceived that would lead inexorably from an early-use to a dystopian situation, with the corollary that is would be unethical to ever attempt germline GM, lest it lead to such eventual disaster. While the general concept of a slippery slope is intuitively attractive to many laypeople and media commentators, it is supported by few ethicists. ${ }^{89}$ This is because the concept lacks a logical basis: why should the first use of any novel biomedical technology inexorably lead to disaster? I suggest that, to qualify as a coherent argument, the onus resides with the proponents of a slippery-slope to establish a plausible and strong link between the early-use of a new technology and the evoked dystopian future.

Of course, possible future Utility-reducing downsides of widespread HGGM can be envisioned, including negative societal effects through genetic inequity, opportunity costs through diversion of resources from alternative projects, and a narrowing of the human gene pool when the technology becomes able to alter large numbers of sequences per embryo. And it has been argued that, just as a slippery slope is a fallacious assumption, it would be unwarranted to assume the existence of a simplistic 'automatic escalator' in which technological improvement leads to some utopia. ${ }^{90}$ However, history demonstrates that progress in medical science and technology has indubitably produced major net benefits for humanity; and there is every reason to believe that further major gains will accrue, commensurate to the extent that bioscientific research is allowed to proceed. ${ }^{91}$ The posited downsides lie far in the future; their probability and magnitude is highly uncertain, and technological or legislative solutions may well emerge to prevent or mitigate them. To proscribe a promising biotechnological development in its initial stages based on possible far-future downsides would be irrational and unconducive to Utility maximisation.

\section{A PRUDENTIAL UTILITARIAN APPROACH}

In the farther future, HGGM is likely to become highly effective and efficient: it is conceivable that it might ultimately be applied to large numbers of people, perhaps in a manner akin to present day immunisation programmes, thereby preventing millions of premature deaths and a great deal of suffering. We cannot know whether the necessary technological developments to reach this stage will take 15,50 , or 100 years, or more: but it is clear that a delay to the start of this journey would postpone the future benefits. If we wait for (say) 10 years before proceeding, that will be 10 years lost, which equates to a substantial forfeiture of Utility. Of course, the people who stand to benefit the most from HGGM do not yet exist; but the happiness of these future people must be included in the Utilitarian calculus.

Thus, a delay in implementing the technology would be a source of Disutility. This does not necessarily mean, however, that it must be right to permit HGGM immediately, without any delay

\footnotetext{
${ }^{89}$ Spielthenner G. (2010). A logical analysis of slippery slope arguments. Health Care Anal. 18(2):148-163.

${ }^{90} \mathrm{~S}$. Holm and T. Takala. High hopes and automatic escalators: a critique of some new arguments in bioethics. $J$ Med Ethics 33; 2007; 33: 1-4.

${ }^{91}$ Pace Holm and Takala (ibid), there is good reason to think that a trend towards Utility-boosting technical improvement does exist in the context of biomedicine. This notion is supported on a theoretical level: because governments sponsor the development of biomedical technology with the aim of providing benefits to society, and the products of biotechnology have a market value (and are thus sustained and further developed) because of the benefits they bring, we might reasonably expect these factors to provide impetus to the improvement of these technologies, thus increasingly yielding Utility. And in practice, the history of biomedical technology has been one of steady improvement from small beginnings, bringing forth a myriad of invaluable innovations: a full list of these technological accomplishments would be very long, ranging from antibiotics to dialysis machines to synthetic insulin, to name but a few areas in which small scientific beginnings have led to major Utility-promoting outcomes. This general history of progress in the domain of medical technology gives reason to be optimistic in regards to HGGM: it appears highly likely that the development and deployment of human HGGM, kickstarted by an early-use attempt such as that with Couple $X$, will yield substantial Utilitygenerating benefits in terms of reducing the burden of genetically influenced disease.
} 
whatsoever. An alternative approach would be to wait a modest period -perhaps one or two yearsto allow the underlying technology to mature further. This delay would entail some Utility loss, because some couples would have more difficulty conceiving later, and some would opt for natural conception in the meantime. But it would also bring several advantages. Efficacy and precision will likely further improve as the basic technology is refined, meaning that the risks of both failure (and the associated burden of IVF cycles) and genetic damage (and associated disease) should be reduced.

While these benefits from a delay would boost Utility, the magnitude of the Utility gain will be low, considering that (as discussed above) current CRISPR technology already offers the ability to reliably alter genetic sequences with relatively low levels of genetic damage. Additionally, a delay that appeared to be based on acceding to the notion that the technology is insufficiently safe might inadvertently lend support to arguments for an indefinite delay, since it will never be possible to know with certainty what the actual safety levels are until the technology is used to create human children. However, a modest delay might offer the pragmatic benefit of allowing public trust to build. If more cellular and in vivo (animal) reports of success are allowed to accumulate, and thus counter residual safety concerns (such as the above-mentioned negative report of Kosicki et al), this may serve to provide reassurance to the public, thereby creating greater acceptance for HGGM.

The recent news that He Jiankui has seemingly created gene-edited human infants is of particular relevance to the question of a delay. As discussed above, this apparent first-attempt at HGGM looks ill-conceived and early indications are that it has not been fully successful; it thus is likely to function as a setback for the start of the HGGM revolution. ${ }^{92}$ If another attempt, such as that suggested for Couple $X$, were also to fail badly, it seems likely that public support for the whole enterprise would be severely impacted, leading to long delays in going forward with HGGM. Thus, although it can be argued that a properly conceived GM attempt, such as that described for the Couple $X$ scenario, might justifiably proceed straightaway, the bad publicity surrounding the first actual attempt at HGGM gives further support to the argument that Utilitarians should support a modest delay, of perhaps one or two years, before moving ahead with further attempts to modify the human germline.

\section{CONCLUSIONS}

A permanent or long-term prohibition on the use of GM technology would be antithetical to progress in biomedical innovation, and hence unethical. Although there exist residual safety concerns about CRISPR, there are strong grounds to believe that the technology could be used to create a GM child at an acceptable level of risk. It is possible to identify plausible cases where the application of HGGM technology, at its current stage of technical development, would bring about direct beneficial consequences for those concerned. Couple $X$ in the foregoing discussion represents a hypothetical candidate case, involving SCA. A successful CRISPR-based HGGM attempt would, despite the burden of the process on the mother, boost Utility in respect of these parents, and their future child, if the child would otherwise have been conceived naturally and thus destined to develop SCA. However, the availability of HGGM may lead to some parents choosing this approach instead of adopting a child, which would be a Disutility since the happiness of orphaned children can be greatly increased through adoption. But a successful early-use attempt would have the wider benefit of serving to kickstart the

\footnotetext{
92 It is instructive to compare this first attempt at HGGM with the pioneering attempt at human IVF in the 1970s. The two experiments have in common a number of ethically questionable features, in particular a failure to publicise or consult in advance. However, the IVF attempt was in the event entirely successful, leading to the birth of a healthy individual; by contrast, the GM experiment appears to have failed in certain respects. Speculatively, had the GM attempt been indubitably successful, its ethically problematic features (i.e. issues of justification, approval and consent) might have been largely ignored, and the ensuing commentary less condemnatory, in the same way that ethically questionable aspects of the IVF experiment were eclipsed by its manifest success.
} 
whole enterprise of HGGM. This means that even if there was an initial net reduction in Utility due to reduced adoption associated with the early use of $\mathrm{GM}$, it would most probably be outweighed by the Utility-generating effects of bringing forward the development of advanced, widely applicable HGGM technology. From a Utilitarian perspective, no principled reasons exist to support a risk-averse 'precautionary' delay on an early-use HGGM attempt. However, a modest delay would have pragmatic benefits, a notion that has been given added impetus by the recent news of an ethically questionable and apparently not entirely successful first attempt at HGGM. I suggest that Utility will be maximised if we kickstart the next biomedical revolution by proceeding not immediately but within around 1-2 years to intervene in the human germline. 


\begin{tabular}{|c|c|}
\hline Comments from Editors and Reviewer & My responses \\
\hline COMMENTS FROM THE EDITORS & \\
\hline $\begin{array}{l}\text { Revise again, addressing (the reviewer's) comments and reducing the paper by } \\
\text { around } 20 \% \text {. }\end{array}$ & $\begin{array}{l}\text { I have revised the paper according to the Reviewer's comments, as set out } \\
\text { below. In so doing I have reduced the overall length. According to Word, this is } \\
\text { now (excluding abstract etc) c. } 11 \mathrm{k} \text { words ( } 11,059 \text { to be precise), meaning a } \\
\text { reduction of c.3,000 words, from the original c. } 14 \mathrm{k}-\mathrm{i} . \mathrm{e} \text {. a reduction of slightly } \\
\text { over } 20 \% \text {. }\end{array}$ \\
\hline REVIEWER'S COMMENTS & \\
\hline $\begin{array}{l}\text { Overall comments: The utilitarian analysis is much improved, from a } \\
\text { philosophical point of view, by the latest revision. This comes at a serious cost, } \\
\text { however, that the length has ballooned out to over } 14,000 \text { words - a short } \\
\text { treatise. Long-form bioethics articles are not inherently problematic, but there is } \\
\text { a danger that the paper will meander, and the central important thrust be lost. } \\
\text { Long-form is better suited towards big-picture analyses of larger issues. This } \\
\text { article, however, is more tightly focused around a specific argument: that a } \\
\text { utilitarian risk-benefit analysis militates in favour of germline gene modification, } \\
\text { if not immediately, within the next few years. } \\
\text { The result is a paper that is alternatively fascinating and frustrating, as one must } \\
\text { wade through a good amount of extraneous material to get to the core } \\
\text { argument. That core argument is very important, however, and is in some ways } \\
\text { particularly novel, at least at this moment in history - I do not know of any } \\
\text { bioethicist post-He Jiankui who is defending the sort of position put forward } \\
\text { here (George Church notwithstanding), and it is very much a position that should } \\
\text { be debated seriously, even if one is strongly opposed to germline modification } \\
\text { within the next three years. The author may want the bulwark of the incredibly } \\
\text { detailed argument to shield themselves from inevitable strong critique if and } \\
\text { when this is published. But often those arguments are not freestanding anyway - } \\
\text { relying on more thorough literature elsewhere (e.g., the Parfitian analysis of } \\
\text { utilitarianism; the problems of the precautionary principle; the techno-optimism } \\
\text { that underpins the central argument). }\end{array}$ & $\begin{array}{l}\text { I am, once again, most grateful to the reviewer for their detailed and insightful } \\
\text { comments. I have endeavoured to address the spirit of the overall comment, } \\
\text { as well as the specific major and minor comments. I have fully accepted the } \\
\text { vast majority of the reviewer's points and suggestions, and amended the paper } \\
\text { accordingly, as set out below. }\end{array}$ \\
\hline
\end{tabular}


The paper is then strong on its merits, but tedious to read. Beyond the specific comments below (none of which are any barrier to publication), I would urge the author to consider points where the argument can be substantially streamlined, and parts cut altogether. It can be a very difficult thing to cut down work that one has toiled over so greatly, but the words of Antoine de Saint-Exupery are relevant here: Perfection is achieved, not when there is nothing left to add, but when there is nothing left to take away.

\section{MAJOR COMMENTS}

1) It's good that the author brings up the historic birth of the first gene-edited babies. I think this should be brought up even earlier, in the introduction - it will be on every reader's minds, and the author should clarify from the outset the relevance of what they have to say to that case.

2) P. 2: The note in the middle paragraph about applicability goes a long way towards making the paper interesting to non-utilitarians. Though, on reading this new version, it occurs to me that the paper is essentially an analysis of whether germline editing has a favourable risk-benefit ratio - something central to much clinical/research ethics work. Maybe worth mentioning?

3) P. 3: It should be explained why germline editing is not a therapy. Is it because therapies apply only to people, and embryos are not people? Or that editing creates a new person? Or that it's inextricably bound up in the act of creation?

4) P. 7: "Utilitarians have good reason to support attempting GM in place of PGD on the basis that it would bring about an important wider benefit, namely the kickstarting of a revolution in germline GM." Why is that such a wider benefit? If in the great majority of cases, PGD is superior to GM, then the benefit would only accrue in a smaller set of cases. Presumably, that benefit relates to rare dual monogenic carriers, polygenic editing and/or enhancement applications. In that case, why not limit trials to those types of cases?

5) P. 7: "parental informed consent for germline GM would seem unlikely to be obtainable in such cases." Parental consent itself doesn't seem likely to be an obstacle - I'm sure you could find gung-ho transhumanist volunteers if you really wanted. If the obstacle is instead that the studies aren't ethically justified because the risks outweigh the benefits, just say that. But given your commitments in this paper, I suspect the real problem is that earliest trials are the riskiest, and therefore should focus on targets of the greatest possible benefit.

I have brought the description into the Intro section, and modified the discursive elements in situ.

I have added a short preceding paragraph to convey this.

This is a very good point. Though to do justice to it would be to open another avenue for detailed discussion, around issues of personal identity. Accordingly, I have altered the wording to clarify the issue, without going into lengthy details, and demoted it to a footnote.

I have amended this to make explicit the broader benefits. In so doing I have emphasised that the wider applications will only be possible once the basic technology starts being used, thus clarifying that limiting GM to those cases is not yet feasible.

On reflection, I realise that this is correct: such volunteers would indeed be there. I have adjusted for this by removing the claim, and leading into the next paragraph with the word 'moreover' (cf. 'nevertheless'). This also sits well with the amendment to the previous tract (as above). 
6) P. 11: “While Utilitarians have reason to support radical changes to laws where the outcome is increased Utility, in practice a move to prevent access to established reproductive technologies (in order to boost adoption) would simply be rejected in an open society." I found this line of argument confusing, and somewhat undermining of the whole paper. If democratic processes trump sound utilitarian reasoning, why bother with this 14,000 word paper at all? We should just go by the popular will. (and indeed, popular will would likely in most contexts reject a thoroughgoing utilitarian framework like that offered in this paper) Presumably, the reply is that this paper is meant (within a democratic context) be part of a conversation over whether and how to regulate GM. In that case, popular rejection of a proposal should not be a reason against the author endorsing that proposal. The logical conclusion of one strand of utilitarian logic (banning IVF) should be put forward honestly.

7) P. 15, paragraph beginning "However, the effect of...": Just as with the preceding paragraph, there is not nearly enough evidence to support with confidence the claim that advancing GM will overall lead to more utility. Great uncertainties include the effect on society (cf genetic inequity objections), opportunity cost (money diverted from higher-utility projects), unknown genetic effects (see, e.g., possible negative effect of CCR5 on lifespand only recently highlighted), feasibility of polygenic editing (and uncertainty over the balance of tradeoffs when *massive* numbers of genes are edited), etc.

8) P. 16: Invocation of the Harm Principle seems out of place. While Mill was of course a utilitarian, the Harm Principle does not itself follow straightforwardly from utilitarianism - it relies on a series of other political assumptions that the author has not defended or endorsed. Moreover, the author doesn't appear to even be deploying the Harm Principle in this very paragraph, when they say: "To do so would be to cause more harm than good, because biomedical innovation which is substantially in the public interest would be stifled in a society that sought to prevent bystander distress by proscribing the use of such technology." This does not appeal to any categorical political prohibition on paternalistic intervention. Nor is the author only arguing *prevention of harm* is the only legitimate goal of the state. Rather, they are simply making a cost-benefit analysis. If the tech were actually weak in benefit, and people *really* opposed to it (reproductive cloning is a good candidate here), the author's logic would militate in favour of a ban, pace Mill.

9) P. 24: "it is reasonable to expect that governments will act to prevent manifestly damaging uses of the technology." This doesn't seem a reasonable assumption at all.
It is good that the reviewer has highlighted my lack of clarity here. My intention was not to imply that democratic process trump Utilitarian reasoning. A more thorough discussion around this -not to mention a discussion of IVF ethics per se- would need many more words to do the issues justice, which would be untenable given the need to reduce length. Thus, after reflection, I have simply removed the problematic paragraph.

These are real concerns, but they are far-future; to see such uncertain possible downsides as reason to stop nascent GM is a form of slippery slope argument. So, I have not retreated from the broad thrust of my argument here, however I have made substantial alterations and added a new paragraph, plus footnotes, to clarify my position and deal with this objection.

On reflection, I agree, and have excised this paragraph. The preceding paragraph covers the direct effects on Utility, and that does enough, without the complication of Millian 'harm'.
As part of reducing the length of the paper, much of the PP material has been cut, and what remains reworked. This includes the assumption highlighted by this review point. 


\section{MINOR COMMENTS}

1) P. 2: The paragraph on Kantians, virtue ethicists, pluralists, etc. could do with a few more citations. In particular, a representative principlist account (Beauchamp and Childress) and casuist take (Albert Jonsen's work?) could be cited.

2) Also, it's probably best to avoid strong claims like "a majority" without evidence; "many" will do.

3) P. 2: I understand the paragraph about utilitarianism not being monolithic was put in in response to the editor's comments. Still, I think this paragraph doesn't add much the paragraph that follows, on varieties of utilitarianism, demonstrates heterogeneity more directly. And it goes without saying that any argument for $\mathrm{X}$ based on $\mathrm{Y}$ theory doesn't speak for all holders of $Y$ theory.

4) Pp. 2-3: Preference satisfaction isn't a form of indirect utilitarianism. Rather, it's an account of the nature of utility - that utility just consists in satisfying preferences. Rule utilitarianism, by contrast (also mentioned in the same sentence), is indeed solidly a form of indirect utilitarianism.

\section{Added.}

Changed.

I agree, and have removed this paragraph; but to also try to satisfy the initial editorial comment, I have placed it as a footnote.

I don't quite agree. While in most cases preference satisfaction will enhance Utility, satisfying an individual's preference does not necessarily lead to greater personal Utility. For example, the individual may be mistaken about the likely benefits of a given choice, or may not have adequate self-knowledge to accurately judge the effects on their Utility of a given choice. Hence I have not changed the wording.

5) P. 3: It would be helpful to very briefly explain why hedonistic utilitarianism is chosen. Is it just easier to adjudicate than other forms, i.e., a pragmatic choice?

6) P. 3: The use of the term 'proband' will be confusing to non-geneticist readers, and in any case I'm not sure it's the accurate term for the subject of gene editing.

I have added a footnote with an explanation.

7) P. 4: Citations are needed in relation to the effectiveness/risks of germline editing

8) P. 4: "...the claimed genetic alterations have not been independently confirmed..." It appears that as of now the Chinese government has confirmed the births: https://www.scmp.com/news/china/science/article/2182964/china-confirms-geneedited-babies-blames-scientist-he-jiankui .

9) P. 8: "Worldwide, a great number of children are languishing in orphanages, undoubtedly experiencing lives that are, on average, of substantially reduced happiness compared with the lives of children in non-institutional settings." Citation with evidence of this claim is needed.

10) P. 10, fn.37, on Average Utilitarianism: "This is irrational, because there is clearly far more Utility in the former world than the latter." This claim is question-begging, by assuming that (within utilitarianism) only total utilitarianism is rational. Of course, there is not space in a footnote to elaborate on these intricacies. I would suggest instead

I have substituted alternative phrasings in the 4 instances of this word (different wordings in each case, specific to the context).

Relevant references were elsewhere in the text; I have relocated the relevant ones to this point, and added 2 more.

Amended to incorporate.

I have amended this to qualify the statement. I have not added a citation, however, as this is a well-known fact, but quantification is not available.

I have changed the paragraph and footnote accordingly. 
cutting all discussion of the failings of alternative utilitarian views, and instead briefly noting that discussion of all their flaws can be found in Parfit (2016). Similarly, the paragraph on the top of page 10 (which will be very difficult for many non-philosophical readers to parse) could also be trimmed down to briefly note that Parfit attempts his own solution, but the overall issue remains unresolved.

11) P.11, on the impact of a rule banning GM: "Of course, this conclusion must be tentative, as predictions of how people would actually feel and respond in the face of such a rule can be made only on the basis of educated guesses." On the contrary, most high-income countries have laws or regulations effectively banning germline modification. What is unknown is the counterfactual: how many people would use GM *instead of* adopting, were the former made available. And evidence can be put forward to answer this counterfactual, by studying the effect of liberalising other reproductive technology (e.g., IVF) on adoption rates. See, e.g., Cohen and Chen (2010), "Trading-Off Reproductive Technology and Adoption: Does Subsidizing IVF Decrease Adoption Rates and Should It Matter?", Minnesota Law Review 95:485-577.

12) P. 14: The last paragraph's first sentence should say “...germline GM actually works, ..."

13) Pp. 14-15: The paragraph at the bottom of 14/top of 15 takes a very long time to make a point that could just as easily be made briefly - especially since the gist (not enough evidence to make a conclusion on utility) has already been explicated earlier in the paper.

14) P. 18: "there is good reason to believe that the low or zero occurrences of mutations and clinically relevant mosaicism reported in most of the recent literature would likely apply to a real-life attempt at germline GM." It may be worth mentioning the He Jiankui case here, which is the only known real-life attempt, and according to reports mosaicism did occur. A response is available, of course - He Jiankui was, among other things, simply bad at the bioscience, and this points towards the need for GM to only be done under well-regulated environments by competent individuals. But still, it's a concern.

\section{5) P. 19: “...accidental CRISPR-induced mutation could not lead to a negative} outcome...": 'not' should be deleted.

16) P. 22: "The strongest version of the PP holds any degree of risk to be unacceptable, irrespective of the potential benefits." Does anyone actually hold this rather absurd and conceptually incoherent (as all actions involve some risk) view? This is a far cry from the view of Sachs (2011), the one author cited defending the Strong PP; they define it as: “(1) regulation should presumptively be applied when an activity or

The first point is true, and I have slightly altered an earlier sentence to emphasise that the rule is relevant only in the future context of germline GM technology becoming available. In terms of the research referred to, this is of relevance and I have incorporated it - albeit as a footnote, because, although interesting, the findings are preliminary and not broadly generalisable.

(Following the next review point, this has been removed.)

Paragraph removed.

This has now been addressed by amendments to the paragraph.

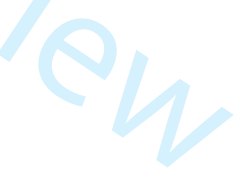

Corrected.

As mentioned above, I have now taken much of the PP material out; it is an area which, on reflection, does not merit such extensive coverage. I have also reworked what remains. 
product poses serious threats to human health or the environment, even if scientific uncertainty precludes a full understanding of the nature or extent of the threats; and (2) the burden of overcoming the presumption in favor of regulation lies with the proponent of the risk-creating activity or product." This neither argues for categorical ban in the face of risk (only regulation), nor is it insensitive to offsetting benefits (instead, puts a burden of proof on those arguing for benefits).

17) P. 23: "Another PP-based objection against proceeding with a germline GM

As above. attempt focuses not on risks to the immediate children who may be created with the initial attempts at germline GM, but with the spectre of distant harms or other negative outcomes." Dystopian objections to GM seem completely separable from the PP, so this would make more sense as a separate section rather than a sub-point in discussion of the PP. Dystopians do not rely on a presumption against risky technology; they instead highlight what they take to be a serious risk of the technology, one that militates against GM even if one weighs risks and benefits evenly.

18) P. 25: "A moratorium on the use of GM technology would be antithetical to progress in biomedical innovation, and hence unethical." This is in direct contrast to the preceding, where the author concedes a 1-2 year delay (i.e., moratorium?) on GM is 